\title{
RESEARCH ON PROPERTIES AND THE HYDRATION OF PORTLAND LIMESTONE CEMENT WITH DIETHANOL-ISOPROPANOLAMINE
}

\author{
XIAOLEI LU ${ }^{*}, * *$, SHUXIAN WANG $*$, CHUANHAI LI $*, * *,{ }^{*}$ ZHENGMAO YE*, $* *,{ }^{*}$ XIN CHENG ${ }^{*}, * *$ \\ *School of Materials Science and Engineering, University of Jinan, \\ Jinan, Shandong 250022, China \\ **Shandong Provincial Key Laboratory of Preparation and Measurement of Building Materials, \\ Jinan, Shandong 250022, China
}

\#E-mail: mse_yezm@163.com (Zhengmao Ye), mse_chengxin@163.com (Xin Cheng)

Submitted December 19, 2017; accepted March 27, 2018

\begin{abstract}
Keywords: Diethanol-isopropanolamine, Portland limestone cement, Properties, Hydration mechanism
Diethanol-isopropanolamine (DEIPA) is a new type of alkanolamine used as grinding aids for Portland cement. In this study, the effect of DEIPA on properties of Portland limestone cement (PLC) were investigated by measuring strength of mortar, setting time, compatibility of cement and superplasticizers. A combination of isothermal calorimetry, scanning electron microscopy and mercury intrusion porosimetry was used to investigate the hydration kinetics. The results indicate that the addition of DEIPA markedly enhances the early and late strength of mortar, which gains a 4.4 MPa increment (28.7\%) at $3 d$ and a $6.3 \mathrm{MPa}$ increment (20.3\%) at 28 d, respectively, and is not significant differences in the setting time. However, the compatibility of cement and superplasticizer becomes poor in the cement paste containing DEIPA. The working mechanism of DEIPA accelerates the hydration of aluminate and alite, and promotes the formation of AFt and monocarboaluminate, as well as the transformation of AFt to AFm. Besides, the addition of DEIPA results in uniformly overlaps hydration products and improves microstructure in hardened cement pastes.
\end{abstract}

\section{INTRODUCTION}

Faced with global energy and environmental problems, the cement industry is being confronted with extensive press coverage due to the large amounts of $\mathrm{CO}_{2}$ emission produced during their manufacturing. In order to reduce the $\mathrm{CO}_{2}$ emission level, one approach is to improve the properties of cement by using additives. Another approach involves adding supplementary cementitious materials of ground granulated blast-furnace slag (GGBFS), fly ash, silica fume, or limestone powder to Portland cement. Nowadays limestone powder is widely used as the supplementary cementitious material in concrete because of its natural availability as well as technical and economic advantages $[1,2]$.

Numerous research groups had studied the effects of limestone powder on the hydration and strength properties of hardened cement pastes. The results showed its presence increased the hydration rate of Portland cement during early stages. Limestone powder mainly played the role of filling, accelerating clinker hydration and reactivity in the process of cement hydration [3, 4]. Besides, limestone powder had the effect of water reducing. A. Scholer [5] studied that the addition of 5 wt. $\%$ of limestone powder exerted a remarkable influence on the hydrate assemblage and had a higher compressive strength after 28 days in quaternary cements. L. Martin [6] investigated the limestone powder significantly accelerated the early hydration kinetics in combination with anhydrite at $\mathrm{M}=1.1$. G. Kakali $[7,8]$ found that the transformation of ettringite (AFt) to calcium mono-sulfoaluminate hydrate (AFm) was delayed in cement pastes containing $\mathrm{CaCO}_{3}$, while calcium aluminate monocarbonate was preferably formed instead of AFm even at early ages. Moreover, the hydration of alite was accelerated. K. De Weerdt [9] also put forward the presence of limestone powder led to the formation of hemi- and monocarbonate and to a stabilisation of $\mathrm{AFt}$ compared to the limestone-free cements. A. Marzouki [10] investigated that adding limestone filler increased material sorptivity and changed porosity characteristics. Liu [11] proposed limestone powder has not pozzolanic activity and was still unhydrated at $28 \mathrm{~d}$, while it can improve the interfacial transition zone of concrete between matrix and aggregate due to its filling effect. H. Temiz [12] reported the test results about mechanical and physical properties of various Portland limestone cement (PLC) mix proportions samples. A. Arora [13] demonstrated that blending GGBFS and limestone powder was used to improve PLC hydration with 
various mix proportions. P.J.M. Monteiro [14] found high-volume natural volcanic pozzolan and limestone powder as partial replacements for portland cement could improved mechanical properties and durability in the self-compacting concrete. X. Wang et al. $[15,16]$ found that blended cements can be optimized to minimize the shortcomings of each component owing to this synergistic effect between limestone powder and fly ash.

Diethanol-isopropanolamine (DEIPA) is a new alkanolamine in cement grinding agents. Figure 1 shows a schematic representation of the chemical structure of DEIPA. There have been a few studies on the influence of DEIPA on the hydration of Portland cement. L. Jardine [17] investigated that DEIPA was preferred for improving early strength when admixed into cementitious compositions. Riding [18] observed that DEIPA increased the early age mortar strength and affected the morphology of calcium hydroxide $(\mathrm{CH})$. Ma $[19,20]$ also observed that DEIPA can increase the early and late strength and promote the formation of AFt and microcrystalline $\mathrm{CH}$ at early stages. J. Cheung [21] reported DEIPA can enhance the compressive strength of the limestone blended cement. Nevertheless, the effect of DEIPA on the properties and hydration process of PLC is unknown. In this work, DEIPA was added into PLC to investigate the effect on properties (compressive strength, setting time and compatibility of cement and superplasticizer) and hydration kinetics. In addition, the mechanism of cement hydration in the presence of DEIPA was discussed.

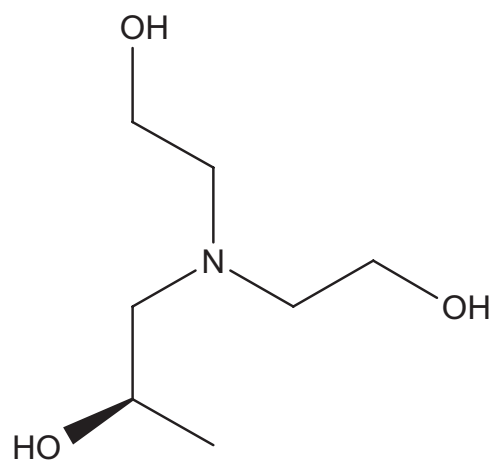

Figure 1. Schematic representation of chemical structure of diethanol-isopropanolamine.

\section{EXPERIMENTAL}

\author{
Raw materials
}

The clinker, limestone and gypsum used in this work were obtained from a Chinese cement company. The chemical and mineralogical composition of the clinker are shown in Table 1. The chemical composition of limestone and gypsum are shown in Table 2. The contents of oxides were measured by X-ray fluorescence. The Bogue method was used to analyze the mineral phases. Research-grade DEIPA was added to Portland limestone cement pastes and its dosage was used by weight of cement of $0.01 \%, 0.02 \%$ and $0.03 \%$. Polycarboxylate superplasticizer with a solid content of $40 \%$ and aliphatic superplasticizer with a solid content of $30 \%$ were used to achieve a flowable cement paste when DEIPA was added. Deionised water was used as the mixing water in the paste experiments.

\section{Sample preparation}

Portland cement (95 wt. \% clinker and 5 wt. \% gypsum) and the limestone powder were respectively ground using a laboratory ball mill with dimensions of $500 \mathrm{~mm} \times$ $\times 500 \mathrm{~mm}$, whose particle size distribution are shown in Table 3. The particle size distribution was measured by using the laser particle size analyzer (BECKMAN

Table 3. Particle size distribution of Portland cement and limestone powder $/ \%$.

\begin{tabular}{lcccc}
\hline Particle size & $<3 \mu \mathrm{m}$ & $3-32 \mu \mathrm{m}$ & $32-65 \mu \mathrm{m}$ & $>65 \mu \mathrm{m}$ \\
\hline Portland cement & 5.86 & 61.21 & 32.11 & 0.82 \\
Limestone powder & 8.24 & 65.32 & 26.03 & 0.41 \\
\hline
\end{tabular}

Table 4. Mix proportions of Portland limestone cement.

\begin{tabular}{lcc}
\hline \multirow{2}{*}{ Sample } & \multicolumn{2}{c}{ Portland limestone cement } \\
\cline { 2 - 3 } & Portland cement & Limestone powder \\
\hline PLC-5 & 95 & 5 \\
PLC-10 & 90 & 10 \\
PLC-15 & 85 & 15 \\
PLC-20 & 80 & 20 \\
PLC-25 & 75 & 25 \\
\hline
\end{tabular}

Table 1. Chemical and mineralogical composition of clinker (wt. \%).

\begin{tabular}{|c|c|c|c|c|c|c|c|c|c|}
\hline \multicolumn{5}{|c|}{ Chemical composition } & \multicolumn{5}{|c|}{ Mineralogical composition } \\
\hline $\mathrm{CaO}$ & $\mathrm{SiO}_{2}$ & $\mathrm{Al}_{2} \mathrm{O}_{3}$ & $\mathrm{Fe}_{2} \mathrm{O}_{3}$ & $\mathrm{MgO}$ & $\mathrm{SO}_{3}$ & $\mathrm{C}_{3} \mathrm{~S}$ & $\mathrm{C}_{2} \mathrm{~S}$ & $\mathrm{C}_{3} \mathrm{~A}$ & $\mathrm{C}_{4} \mathrm{AF}$ \\
\hline 64.18 & 21.08 & 4.70 & 3.49 & 2.79 & 0.38 & 63.28 & 12.69 & 6.54 & 11.52 \\
\hline
\end{tabular}

Table 2. Chemical composition of limestone and gypsum (wt. \%).

\begin{tabular}{lcccccccc}
\hline Chemical composition & $\mathrm{SiO}_{2}$ & $\mathrm{Al}_{2} \mathrm{O}_{3}$ & $\mathrm{Fe}_{2} \mathrm{O}_{3}$ & $\mathrm{CaO}$ & $\mathrm{MgO}$ & $\mathrm{SO}_{3}$ & $\mathrm{~K}_{2} \mathrm{O}$ & $\mathrm{Na}_{2} \mathrm{O}$ \\
\hline Limestone & 5.70 & 1.33 & 0.81 & 52.33 & 2.23 & 0.24 & 0.29 & 0.06 \\
Gypsum & 2.36 & 0.84 & 0.35 & 42.98 & 0.38 & 46.00 & - & - \\
\hline
\end{tabular}


COULTER LS 13 320, U.S.A.). Portland limestone cements were homogenized in the conical mixer $\left(30 \mathrm{rpm} \cdot \mathrm{min}^{-1}\right)$ for $6 \mathrm{~h}$, and its mix proportions are shown in Table 4.

\section{Methodology}

\section{Cement paste preparation}

Measurements of hydration heat evolution and microstructural characterization were carried out on cement pastes which were prepared with a fixed water to cement mass ratio of 0.4 . Cement pastes were prepared by mixing cement and water containing DEIPA using over a time span of $2 \mathrm{~min}$ into the mixer at $62 \mathrm{rpm}$. After a $10 \mathrm{sec}$ interval, mixing was resumed for an additional $2 \mathrm{~min}$ at $125 \mathrm{rpm}$. The fresh pastes were poured into the mold ( $20 \mathrm{~mm}$ by $20 \mathrm{~mm}$ by $20 \mathrm{~mm}$ ). The molds were then covered with the plastic wrap and stored in a curing box with a relative humidity of $98 \%$ and a temperature of $20 \pm 2^{\circ} \mathrm{C}$. The hydration was stopped after $3 \mathrm{~d}$ and $28 \mathrm{~d}$ by submerging small pieces in anhydrous ethanol. The pieces were stored in an oven at $40^{\circ} \mathrm{C}$ for $1 \mathrm{~d}$ to dry. Some dried pieces were retained for SEM and MIP experiments.

\section{Mechanical properties}

The compressive and flexural strengths of mortars were measured according to the Chinese standard GB/ T17671-1999 (ISO). Mortars were prepared with Chinese standard sand, cement and water. A cement powder/ sand/ water weight ratio of 1: 3: 0.5 was employed.

\section{Physical properties}

The setting times and normal consistency of the cement paste were determined in accordance with the Chinese standard GB/T1346-2011 using a Vicat apparatus. Compatibility between Portland limestone cement and superplasticizers was determined according to the Chinese standard JC/T1083-2008 (Test method for compatibility of cement and water-reducing agent).

\section{Isothermal calorimetry}

An eight channel isothermal calorimeter (TAM Air from Thermometric AB, Sweden) was used to investigate the hydration heat flow of Portland limestone cement with and without DEIPA. The calorimeter was first regulated at a constant temperature of $25^{\circ} \mathrm{C}$ and then equilibrated for $24 \mathrm{~h}$. The hydration experiments were measured over a period of $72 \mathrm{~h}$.

\section{Mercury intrusion porosimetry analysis}

The porosity and pore size distribution were studied using a Quantachrome PoreMaster (PM60GT-18, U.S.A.) mercury intrusion porosimeter. A pressure of more than $300 \mathrm{MPa}$ can be achieved by the machine and this pressure allows the mercury to penetrate pores as fine as $5 \mathrm{~nm}$ diameter.

\section{Scanning electron microscopy analysis}

Scanning electron microscopy was used to observe the microscopic morphology of hydration products in the harden cement pastes. Some pieces were coated with carbon and examined using a Quanta FEG-250 SEM operated at $10 \mathrm{kV}$.

\section{RESULTS AND DISCUSSION}

\section{Mechanical properties of mortars}

The strength of mortars at $3 \mathrm{~d}$ and $28 \mathrm{~d}$ are illustrated in Figure 2 and 3, respectively. DEIPA increases the compressive strength along with the hydration process. When the addition of DEIPA is $0.03 \%$, the compressive strength at $3 \mathrm{~d}$ increases by $4.0 \mathrm{MPa}(17.7 \%)$ in PLC10 specimen. With the increase of limestone powder content, DEIPA significantly improves the strength of the mortars at $3 \mathrm{~d}$ and $28 \mathrm{~d}$. The compressive strength of PLC-20 specimen has the largest improvement in the dosage of $0.02 \%$, and increases by $4.4 \mathrm{MPa}(28.7 \%)$ at $3 \mathrm{~d}$ and $6.3 \mathrm{MPa}(20.3 \%)$ at $28 \mathrm{~d}$, respectively. However, the amplification of strength is lower for the mortars with

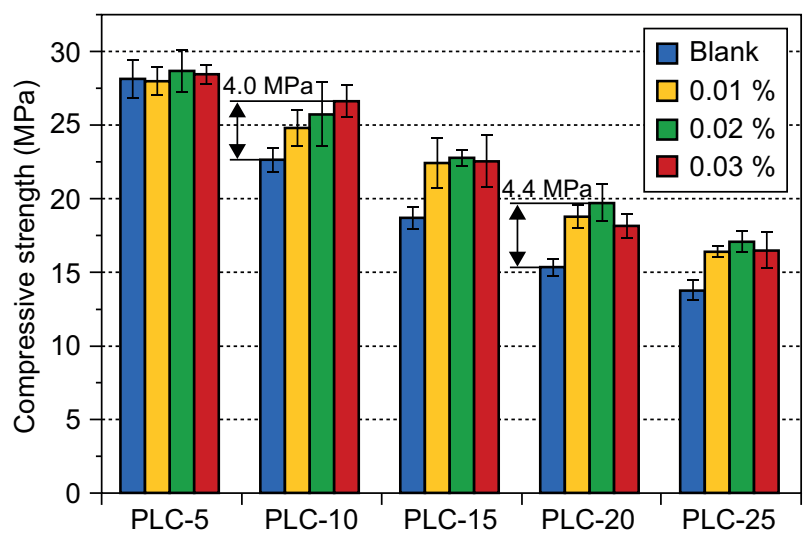

Figure 2. Compressive strength of mortars in different dosages of DEIPA at $3 \mathrm{~d}$.

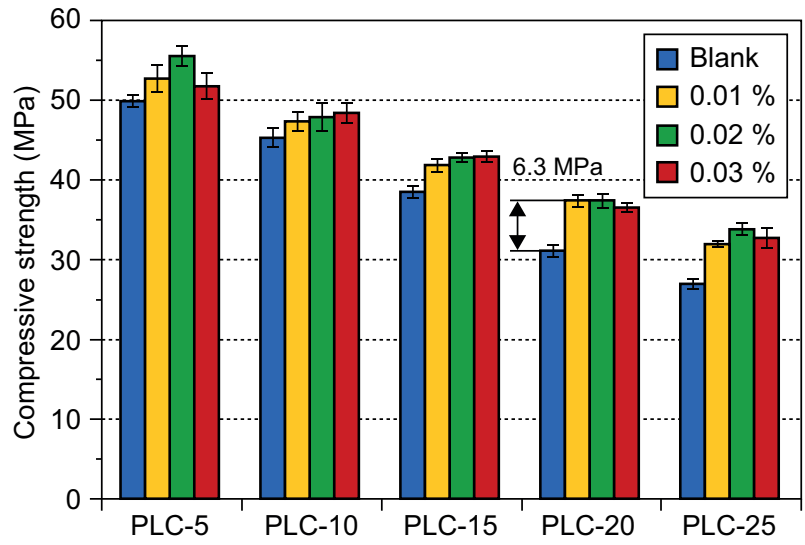

Figure 3. Compressive strength of mortars in different dosages of DEIPA at $28 \mathrm{~d}$. 
DEIPA in the PLC-25 specimen, and the compressive strength of mortars are slightly increased with DEIPA at $3 \mathrm{~d}$ and $28 \mathrm{~d}$ in the PLC-5 specimen. DEIPA slightly increases the strength of mortars when the addition of limestone powder is $5 \mathrm{wt}$. \%, while it notably facilitates the strength of mortars for the limestone powder between 10 wt. $\%$ and 25 wt. \%. This results suggest that the limestone powder has the optimum dosage (20 wt. \%) for blended cement in the presence of DEIPA, namely the largest improvement to strength in the PLC-20 specimen. In addition, the addition of DEIPA significantly increases the early strength at $3 \mathrm{~d}$ and the late strength at $28 \mathrm{~d}$, illustrating that DEIPA accelerates the hydration of cement and decreases the porosity of hardened cement pastes, which is in agreement with the analysis of isothermal calorimetry and pore structure in later part of this paper.

\section{Physical properties of Portland limestone cement}

The quantities of water required for a normal consistency, setting time and fluidity of cement paste are shown in Table 5. As a result of the addition of DEIPA, the quantity of water requirement increased for a normal consistency in cement pastes. The setting time of the samples without and with DEIPA achieved the requirements of Chinese standard, which requires the initial setting time to be more than $45 \mathrm{~min}$ and the final setting time to be less than $390 \mathrm{~min}$ [22]. The initial and final setting times of the PLC-20 specimen are slightly shorten for the cement paste with $0.02 \%$ DEIPA compared without DEIPA. In addition, the influence of DEIPA on the fluidity in cement paste is similar with two superplasticizers. The value of fluidity in the cement paste notably decreases with DEIPA compared without DEIPA. Generally, the result would be considered as the good compatibility if the value of fluidity is little change in the cement paste with and without additives [23, 24]. The result indicates the poor compatibility is produced between Portland limestone cement paste with DEIPA and superplasticizers. It is likely that superplasticizers are covered by more hydration products which are formed due to the presence of DEIPA, consequently, leading to the decrease in the fluidity of cement paste $[25,26]$.

Isothermal calorimetry
Figure 4 presents the exothermic heat flow of cement hydration in Portland limestone cement pastes with and without DEIPA. As shown in Figure 4, it is seen that the addition of DEIPA results in visible changes in the hydration of cement. The heat release curves are characterized by the presence of three peaks in $72 \mathrm{~h}$. The initial peak is assigned to the dissolution of free lime, aluminate, alite and the initial precipitation of AFt [27-29], and a larger increase is observed in the aluminate peaks with DEIPA. The second peak is primarily attributed to the rapid dissolution of alite and the precipitation of the $\mathrm{CH}$ and $\mathrm{C}-\mathrm{S}-\mathrm{H}$ gel phases [30]. There is a very significant increase on the hydration of alite from the use of DEIPA. The third peak also shows a larger increase compared with the one without DEIPA which is associated with the secondary hydration of $\mathrm{C}_{3} \mathrm{~A}$ and the conversion of AFt to $\mathrm{AFm}[29,30]$. In addition, gypsum is exhausted ahead due to DEIPA accelerating the initial and secondary hydration of $\mathrm{C}_{3} \mathrm{~A}$. Hence, calcium carboaluminate hydrate is formed by the reaction of limestone powder with hydrated calcium aluminate. The cumulative heat with the hydration time is shown in Figure 5. Adding DEIPA markedly increases the cumulative heat of the Portland limestone cement. It suggests that DEIPA promotes the hydration reaction of cement particles at $72 \mathrm{~h}$, which leads probably to the decrease in porosity of the hardened cement pastes.

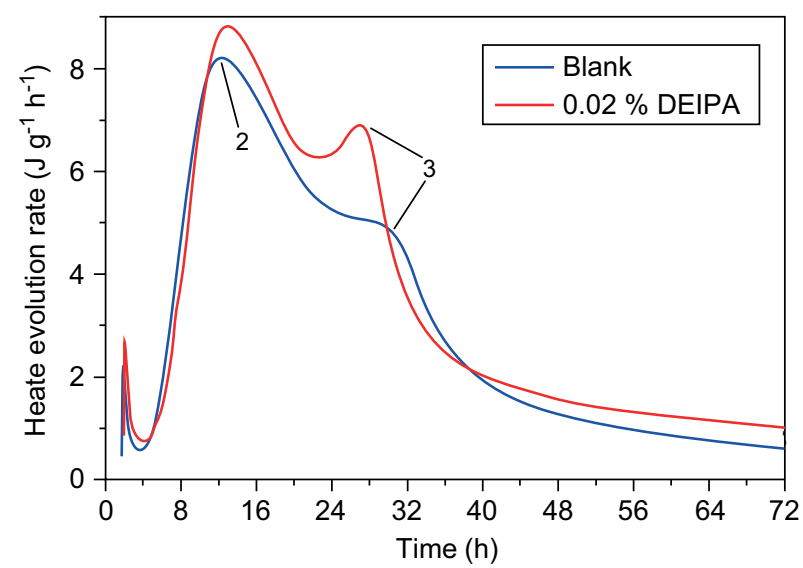

Figure 4. Heat evolution rate of PLC paste (the PLC-20 specimen) with and without DEIPA.

Table 5. Physical properties of the PLC-20 specimen without and with $0.02 \%$ DEIPA.

\begin{tabular}{|c|c|c|c|c|c|c|c|c|}
\hline \multirow[b]{2}{*}{ Sample } & \multirow{2}{*}{$\begin{array}{c}\text { Standard consistency } \\
\text { water demand } \\
(\%)\end{array}$} & \multicolumn{2}{|c|}{ Setting time $(\mathrm{min})$} & \multicolumn{5}{|c|}{ Fluidity of cement pastes (mm) } \\
\hline & & Initial & Final & $\begin{array}{c}\text { Kinds of } \\
\text { superplasticzer }\end{array}$ & $\begin{array}{c}\text { Dosages of } \\
\text { superplasticzer }(\%)\end{array}$ & Initial & $30 \mathrm{~min}$ & $60 \mathrm{~min}$ \\
\hline \multirow{2}{*}{ Without DEIPA } & \multirow{2}{*}{27.5} & \multirow{2}{*}{95} & \multirow{2}{*}{155} & SFAs & 2.0 & 307 & 264 & 207 \\
\hline & & & & PCEs & 0.3 & 212 & 135 & 133 \\
\hline \multirow{2}{*}{$0.02 \%$ DEIPA } & \multirow{2}{*}{28.4} & \multirow{2}{*}{80} & \multirow{2}{*}{135} & SFAs & 2.0 & 257 & 167 & 135 \\
\hline & & & & PCEs & 0.3 & 192 & 0 & 0 \\
\hline
\end{tabular}




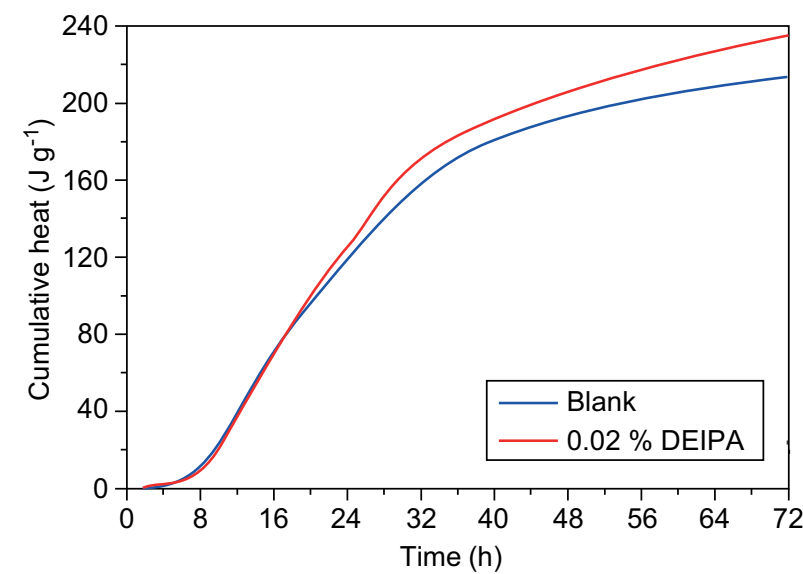

Figure 5. Cumulative heat of PLC paste (the PLC-20 specimen) with and without DEIPA.

Pore size distribution

The effect of the addition of DEIPA on the pore size distribution of hardened cement paste (the PLC-20 specimen) is evaluated and the results are illustrated in Figure 6. It can be clearly that a decrease trend of the accumulative pore volume is observed in hardened cement paste with DEIPA compared without DEIPA. When the pore size ranges from $50 \mathrm{~nm}$ to $1000 \mathrm{~nm}$, the cumulative volume is significantly less for the hardened cement paste with $0.02 \%$ DEIPA, indicating that DEIPA can reduce the size of large pores and increase the size of small pores. It is probably that more capillary pores in hardened cement paste are filled with hydration products which are formed by DEIPA accelerating the hydration of cement. In addition, the mechanical properties of hardened cement paste depend not only on the pore size distribution but also on the porosity. The addition of DEIPA notably decreases the porosity of hardened cement pastes, which corresponds to the analysis of

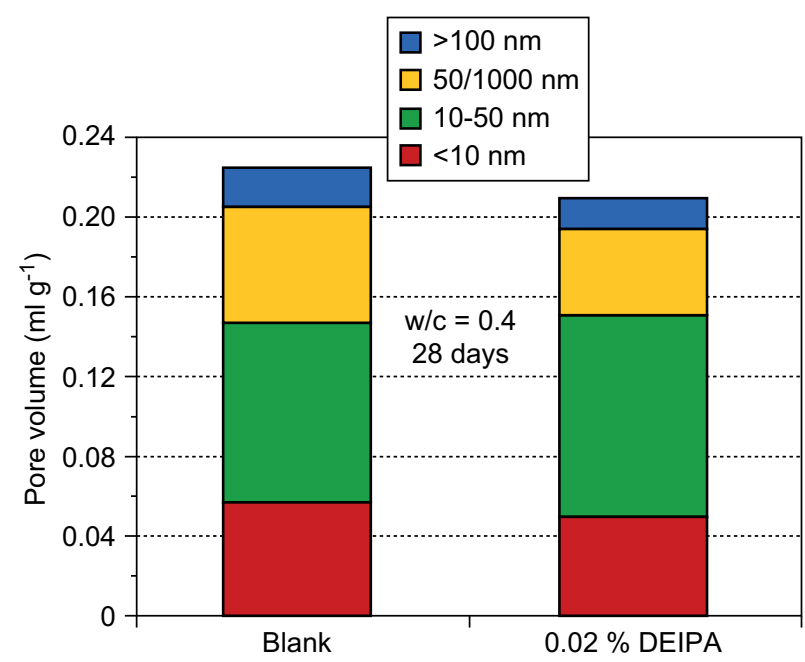

Figure 6. Pore volume of hardened cement paste without and with DEIPA hydrated for $28 \mathrm{~d}$. strength tests in foregoing part of this paper. Based on the above results it can be concluded that DEIPA promotes the hydration process of Portland limestone cement, which finally leads to a more compact structure of the hardened paste. Consequently, the mortar containing DEIPA has a higher compressive strength.

\section{Morphology analysis}

SEM images of the PLC-20 specimens without and with DEIPA hardened cement pastes for $3 \mathrm{~d}$ and 28 $\mathrm{d}$ are presented in Figure 7. For the PLC-20 specimen without DEIPA, typical acicular AFt crystals with size of microns are observed at $3 \mathrm{~d}$. In comparison, with the addition of $0.02 \%$ DEIPA, the morphology of the AFt crystals with markedly stubby rods and much smaller size are present in the hardened cement paste. The

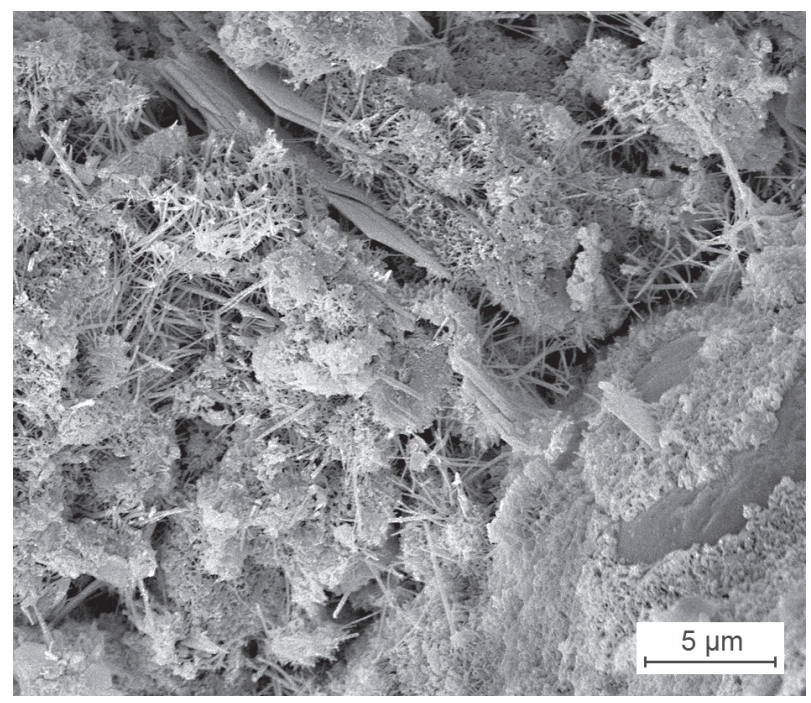

a) PLC-20 specimen without DEIPA at $3 \mathrm{~d}$

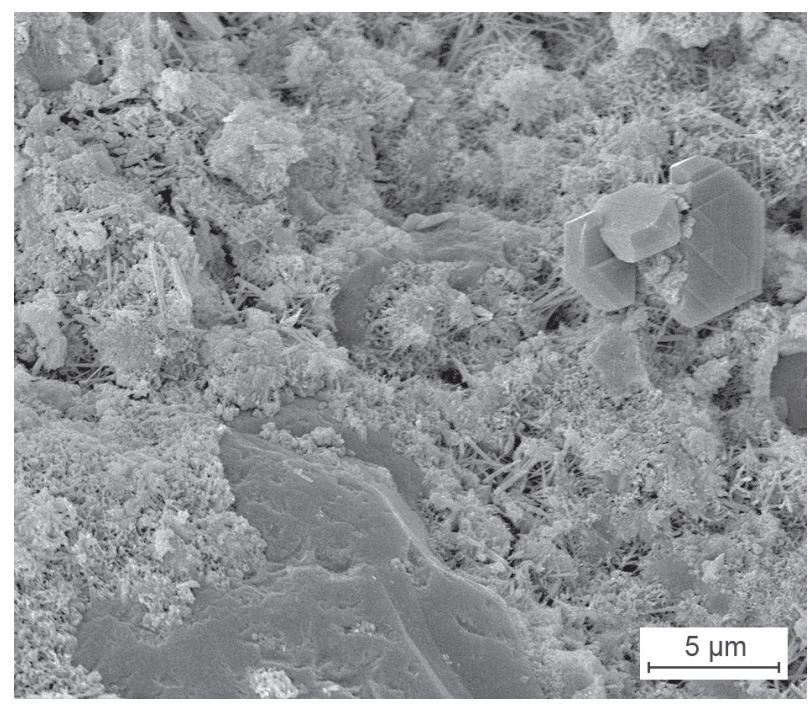

b) PLC-20 specimen with $0.02 \%$ DEIPA at $3 \mathrm{~d}$

Figure 7. SEM images of hardened cement pastes for $3 \mathrm{~d}$ and $28 \mathrm{~d}$ without and with DEIPA. (Continue on next page) 


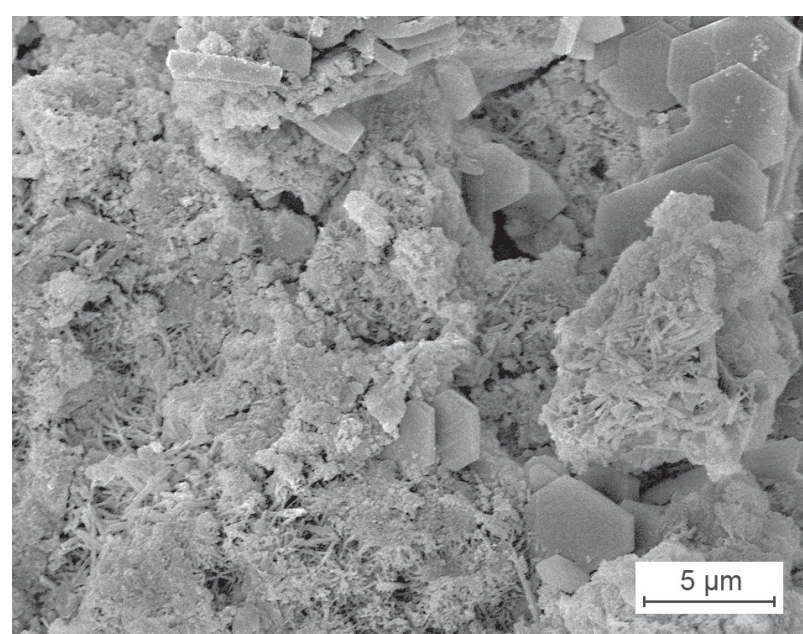

c) PLC-20 specimen without DEIPA at $28 \mathrm{~d}$

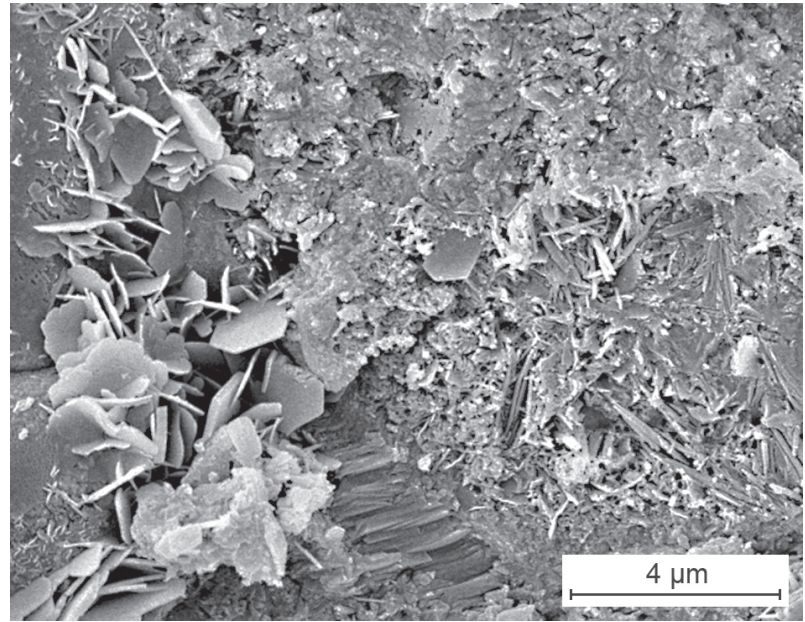

d) PLC-20 specimen with $0.02 \%$ DEIPA at $28 \mathrm{~d}$

Figure 7. SEM images of hardened cement pastes for $3 \mathrm{~d}$ and $28 \mathrm{~d}$ without and with DEIPA.

adsorption of DEIPA containing cation in aqueous phase on the freshly formed AFt surface leads to the growth of AFt being hindered with c-axis [31]. Meanwhile, the content of AFt with adding DEIPA is more than the PLC20 specimens without DEIPA. It is indicated that $\mathrm{AFt}$ phase has already transformed AFm at the hydration of $3 \mathrm{~d}$, which also coincide well with the third peak from isothermal calorimetry. In addition, the mircostructure of hardened cement paste at $3 \mathrm{~d}$ is more compact due to the pore being filled with numerous amorphous $\mathrm{C}-\mathrm{S}-\mathrm{H}$ gel in the presence of DEIPA. Thus, it can be drawn that DEIPA promotes the hydration of aluminate and alite, and the formation of monocarboaluminate. After a hydration duration of $28 \mathrm{~d}$, numerous thin plates are observed in hardened cement paste with $0.02 \%$ DEIPA compared without DEIPA. These thin plates are considered as AFm and monocarboaluminate [32,33]. It is probably to be related to the AFt phase containing DEIPA molecule within the crystal is metastable and tends to transform for the stable AFm phase.

\section{CONCLUSIONS}

The following conclusions can be drawn from this study on the effect of DEIPA on the properties and hydration process of Portland limestone cement:

- The addition of DEIPA increases the early and late strength of mortar. The compressive strength of PLC-20 specimen (20 wt. \% limestone powder) has the largest improvement in the dosage of $0.02 \%$, and increases by $4.4 \mathrm{MPa}(28.7 \%)$ at $3 \mathrm{~d}$ and $6.3 \mathrm{MPa}$ $(20.3 \%)$ at $28 \mathrm{~d}$, respectively.

- The initial and final setting times are slightly decreased to the cement paste with DEIPA. However, the value of fluidity in the cement paste notably decreases with DEIPA compared without DEIPA.

- The working mechanism of DEIPA accelerates the hydration of aluminate and alite, and promotes the formation of $\mathrm{AFt}$ and monocarboaluminate, as well as the transformation of AFt to AFm.

- The addition of DEIPA results in uniformly overlapped hydration products and improves microstructure in hardened cement pastes.

\section{Acknowledgements}

The authors are grateful for the financial support of the National Key Research and Development Program (2016YFB0303505), the National Natural Science Foundation of China (Grant No.51272092 and 51772129), and the 111 Project of International Corporation on Advanced Cement-based Materials (No. D17001).

\section{REFERENCES}

1. Ghosh S., Shondeep L., Sarkar S., et al. (1993). Mineral Admixtures in Cement and Concrete. ABI Books, New Delhi, India.

2. Baron J., Dourve C. (1987): Technical and economical aspects of the use of limestone filler additions in cement. American Journal of Neuroradiology. 34 (2), 360-365.

3. Yang H., Fang K., Tu S., et al. (2006): The effect and its mechanism of calcium carbonate on the cement based materials. Concrete, 6, 32-35. doi:10.3969/j.issn.1002-3550. 2006.06.010

4. Liu S., Yan P. (2008): Action Mechanism of Limestone Powder in Hydration of Complex Binder. Cement Engineering, 6, 6-8. doi:10.3969/j.issn.1007-0389.2008.06.002

5. Scholer A., Lothenbach B., Winnefeld F., et al. (2015): Hydration of quaternary Portland cement blends containing blast-furnace slag, siliceous fly ash and limestone powder. Cement and Concrete Composites, 55, 374-382. doi:10.1016/j.cemconcomp.2014.10.001

6. Martin L., Winnefeld F., Muller C., et al. (2015): Contribution of limestone to the hydration of calcium sulfoaluminate cement. Cement and Concrete Composites, 62, 204-211. doi:10.1016/j.cemconcomp.2015.07.005

7. Kakali G., Tsivilis S., Aggeli E., et al. (2000): Hydration 
products of $\mathrm{C}_{3} \mathrm{~A}, \mathrm{C}_{3} \mathrm{~S}$ and Portland cement in the presence of $\mathrm{CaCO}_{3}$. Cement and Concrete Research, 30 (7), 1073-1077. doi:10.1016/S0008-8846(00)00292-1

8. Voglisa N., Kakalia G., Chaniotakis E. (2005): Portlandlimestone cements. Their properties and hydration compared to those of other composite cements. Cement and Concrete Composites, 27 (2), 191-196. doi:10.1016/j. cemconcomp.2004.02.006

9. Klaartje De Weerdt., Ben Haha M., Le Saout G., et al. (2011): Hydration mechanisms of ternary Portland cements containing limestone powder and fly ash. Cement and Concrete Research, 41, 279-291. doi:10.1016/j.cemconres. 2010.11.014

10. Marzouki A., Lecomte A., Beddey A., et al. (2013): The effects of grinding on the properties of Portland-limestone cement. Construction and Building Materials, 48, 1145-1155. doi:10.1016/j.conbuildmat.2013.07.053

11. Liu S., Yan P. (2010): Effect of Limestone Powder on Microstructure of Concrete. Journal of Wuhan University of Technology-Mater. 25 (2), 328-331. doi: 10.1007/s11595010-2328-5

12. Temiz H., Kantarci F. (2014): Investigation of durability of CEM II B-M mortars and concrete with limestone powder, calcite powder and fly ash. Construction and Building Materials, 68, 517-524. doi:10.1016/j.conbuildmat.2014. 06.078

13. Arora A., Sant G., Neithalath N. (2016): Ternary blends containing slag and interground/blended limestone: hydration, strength, and pore structure. Construction and Building Materials, 102, 113-124. doi:10.1016/j.conbuildmat.2015. 10.179

14. Celik K., Mehta P. K., Monteiro P. J. M., et al. (2014): Highvolume natural volcanic pozzolan and limestone powder as partial replacements for portland cement in self-compacting and sustainable concrete. Cement and Concrete Composites, 45 (1), 136-147. doi:10.1016/j.cemconcomp.2013.09.003

15. Wang X. (2018): Analysis of hydration and strength optimization of cement-fly ash-limestone ternary blended concrete. Construction and Building Materials, 166, 130140. doi:10.1016/j.conbuildmat.2018.01.058

16. Klaartje De Weerdt., Kjellsen K., Sellevold E., et al. (2011): Synergy between fly ash and limestone powder in ternary cements. Cement and Concrete Composites, 33, 30-38. doi:10.1016/j.cemconcomp.2010.09.006

17. Jardine L. (2007). Amine-containing cement processing additives. US Patent No.: 7160384B2

18. Riding K., Silva D., Scrivener K. (2010): Early age strength enhancement of blend systems by $\mathrm{CaCl}_{2}$ and diethanolisopropanolamine. Cement and Concrete Research, 30 (7), 935-946. doi:10.1016/j.cemconres.2010.01.008

19. Xu Z., Li W., Sun J., et al. (2017): Research on cement hydration and hardening with different alkanolamines. Construction and Building Materials, 141, 113-124. doi:10.1016/j.conbuildmat.2017.03.010

20. Ma S., Li W., Zhang S., et al. (2015): Study on the hydration and microstructure of Portland cement containing diethanolisopropanolamine. Cement and Concrete Research, 67, 122-130. doi:10.1016/j.cemconres.2014.09.002

21. Cheung J., Myers D. (2000). Processing additives for hydraulic cements. US Patent No.: 6048393

22. GBT 1346-2011 (2011): Test methods for water requirement of normal consistency, setting time and soundness of the Portland cement. Chinese National Standard.

23. Han S., Yan P., An M. (2014): Compatibility of surerplasticizers in cement paster with low sulfate content. Journal of the Chinese Ceramic Society, 42 (8), 981-988. doi:10.7521/ j.issn.0454-5648.2014.08.05

24. Alonso M., Palacios M., Puertas F. (2013): Compatibility between polycarboxylate-based admixtures and blendedcement pastes. Cement and Concrete Composites, 35 (1), 151-162. doi:10.1016/j.cemconcomp.2012.08.020

25. Dalas F., Pourchet S., Rinaldi D., et al. (2015): Modification of the rate of formation and surface area of ettringite by polycarboxylate ether superplasticizers during early $\mathrm{C}_{3} \mathrm{~A}-\mathrm{CaSO}_{4}$ hydration. Cement and Concrete Research, 69 , 105-113. doi:10.1016/j.cemconres.2014.12.007

26. Knapen E., Van Gemert D. (2009): Cement hydration and microstructure formation in the presence of water-soluble polymers. Cement and Concrete Research, 39, 6-13. doi:10.1016/j.cemconres.2008.10.003

27. Hesse C., Goetz-Neunhoeffer F., Neubauer J. (2011): A new approach in quantitative in-situ XRD of cement pastes: correlation of heat flow curves with early hydration reactions. Cement and Concrete Research, 41 (1), 123-128. doi:10.1016/j.cemconres. 2010.09.014

28. Jansen D., Goetz-Neunhoeffer F., Stabler C., et al. (2011): A remastered external standard method applied to the quantification of early OPC hydration. Cement and Concrete Research, 41 (6), 602-608. doi:10.1016/j.cemconres.2011. 03.004

29. Jansen D., Goetz-Neunhoeffer F., Lothenbach B., et al. (2012): The early hydration of Ordinary Portland Cement (OPC): an approach comparing measured heat flow with calculated heat flow from QXRD. Cement and Concrete Research, 42 (1), 134-138. doi:10.1016/j.cemconres.2011. 09.001

30. Taylor H. F. W. (1990). Cement chemistry. Thomas Telford Publishing, London.

31. Zhang Y., Kong X. (2016): Influence of triethanolamine on the hydration product of portlandite in cement paste and the mechanism. Cement and Concrete Research, 87 (9), 64-76. doi:10.1016/j.cemconres.2016.05.009

32. Bentz D. (2006): Modeling the influence of limestone filler on cement hydration using CEMHYD3D. Cement and Concrete Composites, 28 (2), 204-211. doi:10.1016/j. cemconcomp.2005.10.006

33. Scrivener K., Kirkpatrick R. (2008): Innovation in use and research on cementitious material. Cement and Concrete Research, 38 (2), 128-136. doi:10.1016/j.cemconres.2007. 09.025 